Peer-Reviewed Article
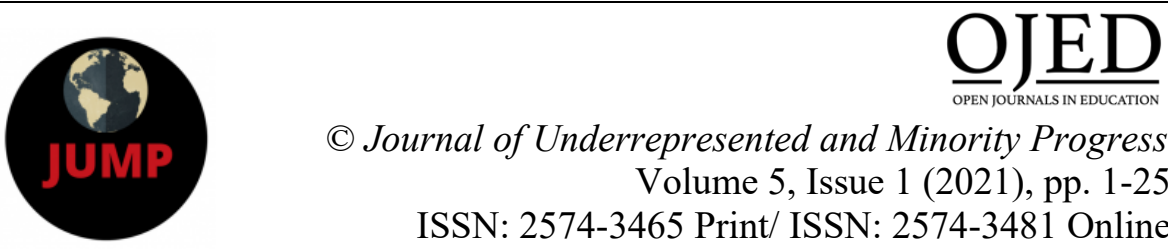

(C) Journal of Underrepresented and Minority Progress

Volume 5, Issue 1 (2021), pp. 1-25

ISSN: 2574-3465 Print/ ISSN: 2574-3481 Online

http://ojed.org/jump

\title{
A Decolonial Approach to Leadership: Latin American Women in the Greater Toronto Area (GTA), Canada
}

\author{
Marisol D'Andrea \\ Toronto, Canada
}

\begin{abstract}
The absence of Latin American women in positions of authority and power is indicative of the career limitations they face. This paper examines the leadership experiences of Latin American women who are leaders and reside in the Greater Toronto Area (GTA). I apply a decolonial feminism approach and the concept of intersectionality to examine the intersection of race, gender, and class. Also, I employ qualitative research using $10 \mathrm{in}$-depth semistructured, individual interviews. I find that current Latin American women leaders still face barriers that prevent them from continuing their advancement in leadership positions. These barriers include racial and gender discrimination, negative stereotypes, scarcity of networks and mentors, and the struggle to achieve a work-life balance.
\end{abstract}

Keywords: Barriers, Decolonial, Gender, Intersectionality, Latin American women, Minority, Stereotype, Work-life balance 


\section{INTRODUCTION}

Over the past decade, although women have made strides in terms of positioning themselves to move onto the leadership path, globally, they face significant barriers to inclusion and prosperity in their careers (Chin, 2010; Pew Research, 2015), such as stereotyping, discrimination, gender issues and work-life balance.

In Canada, Latin American immigrants are the sixth largest among incoming groups, and Spanish is the fifth most common mother tongue there, other than the two official languages, English and French (Corbeil, 2019). The absence of Latin American women in positions of authority and power is indicative of the career limitations they face. Women who are able to rise through the ranks eventually are faced with invisible barriers in making progress (Eagly \& Carli, 2012), while in particular, the progress of women of colour and different ethnicity in leadership are not well-documented, as they have been largely ignored in research (Sanchez-Hucles and Davis, 2010; Turchick-Hakak, Holzinger, \& Zikic, 2010).

Researchers in the U.S.A. state that "Latinas have been somewhat difficult to study because they are racially/phenotypically ambiguous" (Rosette, Koval, Ma, \& Livingston, 2016, p. 441). In Canada, Latin American groups' study is limited; this group remains underrepresented in the research. Because of the lack of Canadian studies on this topic, I rely on American literature. The glass ceiling is still a barrier for leadership positions in middle and upper management (Chin, 2010).

Canada's Employment Equity Act defines "visible minorities as 'persons, other than Aboriginal peoples, who are non-Caucasian in race or non-white in colour'... The visible minority population consists mainly of the following groups: South Asian, Chinese, Black, Filipino, Latin American, Arab, Southeast Asian, West Asian, Korean and Japanese" (Statistics Canada, 2016, para. 2 \& 7).

Although Latin Americans in Canada are more likely to hold a university certificate, diploma, or degree compared to the overall population (Corbeil, 2019), their educational outcomes related to their careers are overlooked (interviews). Hence, there is a gap in the literature between Latin American women leaders' experiences and their educational achievements. This study addresses that gap and focuses on the phenomenon of 'leadership' - a unit of analysis - to examine the leadership experiences of Latin American women who are leaders and reside in the Greater Toronto Area (GTA). I also apply a decolonial feminism approach, which considers the transformation of colonial relations of power and colonial ways to explore 
how Latin American women overcome coloniality in leadership, as well as the concept of intersectionality to examine the intersection of race, gender and class.

This study employs qualitative research using 10 in-depth semistructured, individual interviews. The participants comprised Latin American women in current leadership positions in different fields in the GTA. I have selected the GTA as a subpopulation of Canada because Spanish-speaking people living in Canada tend to gravitate toward the larger cities of Toronto, Montreal and Vancouver (telegram.com, n.a.). Hence, this study is guided by the research question: What are the leadership experiences of Latin American women in the GTA?

This research study finds that current Latin American women leaders still face barriers that prevent them from continuing their advancement in leadership positions. These barriers have been listed under gender relations, racial and gender discrimination, negative stereotypes, scarcity of networks and mentors, and the struggle to achieve a work-life balance. Furthermore, the findings show that minority Latin American women leaders need to assert themselves and work harder than their white, female counterparts in order to overcome stereotypes.

This paper contributes to the literature on minority women in leadership and ethnic diversity. It also helps to give voice to those underrepresented and invisible, opening them to have their voices heard. The study is concerned with the correction of the intersectional invisibility of the female leadership experience in ways relevant to social change and decolonization.

\section{(Minority) Women in Leadership}

\section{LITERATURE REVIEW}

In our contemporary world, the glass ceiling (barrier to advancement in a profession, especially affecting women and members of minorities) remains an issue (Cross, 2010), as do androcentric views (Trinidad \& Normore, 2005) in the workplace. The construct of leadership is suffering from androcentric bias, where the world is seen through a male lens (Trinidad $\&$ Normore, 2005). For instance, a participant explained that often work tasks are gendered. Natalia explains that when it was necessary to organize a baby shower for a colleague, the female in the group was immediately picked for the task. The female employee questioned the selection, refused to take on the task and said, "Why don't you ask the males?" Elements of gender, race, and class are still entrenched in our society, negatively affecting minority women's advancement in an organization. Other factors affecting career 
advancement include work-family conflict and lack of senior or visibly female role models (Cross, 2010).

Generally, women's leadership has been extensively researched (Eagly \& Carli, 2012; Eagly \& Chin, 2010), and hence, gender has become a significant construct in the leadership literature (Stanford, Oates \& Flores, 1995). However, female leaders' absence in the workplaces persists (Alan, Ertac, Kubilay, \& Loranth, 2020; Schuh, Bark, Van Quaquebeke, Hossiep, Frieg, Van Dick, 2014).

Minority women face additional challenges to advance in their careers or rise in management. A substantial body of literature demonstrates the barriers experienced by "women and minorities aspiring for a higher ranking position in organizational hierarchies, as well as identifying the contextual factors that reproduce gender inequalities and significantly reduce women's likelihood of being promoted to leadership positions" (Gotsis \& Grimani, p. 245). In her studies, Campbell (2009) interviewed 14 minority women in the U.S.A. who talk about what it took for them to rise to the top and the obstacles they encountered. These obstacles are framed in terms of societal barriers (such as lack of opportunity, stereotypes, prejudice, and bias), governmental barriers (e.g., inadequate reporting in employment-related data and the dissemination of information as it pertains to glass-ceiling issues), and internal barriers (e.g., inadequate outreach, lack of mentoring, training, and opportunities for career advancement, among others).

Historically, certain people and groups have had difficulty emerging or being perceived as leaders and are therefore less able to exert influence (Rast III, Hogg \& Randsley de Moura, 2018). Rosette and Livingston (2012) argue that minority "women possess not just one, but two, subordinate identities - neither of which has been shown to be particularly typical of the leader role - they will be perceived most negatively in a context of failure" (p. 1163) when compared to male counterparts and white women. In general, women and ethnic minorities face obstacles, both when being considered for a leadership position and when achieving a leadership role, because of their two subordinate identities (Rosette \& Livingston, 2012).

Eagly and Chin (2010) argue that scholars of leadership have infrequently addressed the diversity of leaders in terms of, in particular, race and ethnicity. Diversity issues in leadership are often underexplored and neglected (Gotsis \& Grimani, 2016; Chin, 2010). This omission has undermined the ability to address: "(a) the limited access of individuals from diverse identity groups to leadership roles; (b) the shaping of leaders' behavior by their dual identities as leaders and members of gender, racial, ethnic, or other identity groups; and (c) the potential of individuals from 
groups formerly excluded from leadership roles to provide excellent leadership because of their differences from traditional leaders" (Eagly \& Chin, 2010, p. 216). Powerful women are scarce (Ibarra, Ely \& Kolb, 2013), but powerful minority women are even more so.

Sensoy and DiAngelo (2017) argue that "Minoritized groups often have the wider view of society in that they must understand both their own and their dominant group's perspective - and developed a double consciousness - to succeed." (p. 70). Minority groups are in the margins; they are viewed as the least legitimate in society, dismissed via expressions such as "they just have a chip on their shoulder, ... complain too much, or ... want special rights" (Sensoy \& DiAngelo 2017, p. 70). Women still have limited access to authority, power, and influence, whereas barriers to leadership play a more significant role for minority women (Stryker, 2018). Certainly, in this study, minority women had a burden of learning to navigate their careers through the margins and legitimatize their position in society.

\section{Methodology}

\section{RESEARCH METHODS}

This study examines the lived experience of leadership by Latin American minority women in the GTA. Using a qualitative research and phenomenology approach, it explores the unit of analysis - leadership. Phenomenology is the study of lived experience (Groenewald, 2004; Laverty, 2003; Sloan \& Bowe, 2014; van Manen, 1997), which aims to explore participants' lived leadership experiences and how they interpret those experiences. Phenomenology seeks to return to the concrete, remaining true to the facts, and capturing rich descriptions of lived experiences (Groenewald, 2004). After, in the analysis, I incorporate my experiences into the discussion.

The primary data collection comes in the form of in-depth, semistructured individual interviews. I interviewed 10 participants comprising Latin American women (from Argentina, Colombia, Chile, Ecuador, El Salvador, Mexico, Peru, and Venezuela) in leadership positions in the Greater Toronto Area (GTA). They were women immigrants to Canada who were born in the respective Latin American countries and spoke Spanish. Upon consent, the interviews took place at the site that was most convenient for participants (e.g., office space).

For a phenomenology study, researchers would agree that two to 10 participants are often sufficient to reach saturation (Creswell \& Poth, 2017; Groenewald, 2004). The interviews were audio-recorded and then transcribed verbatim. The mean length of the interviews was 65 minutes. A transcriber helped me transcribe the interviews verbatim. Confidentiality remained at all 
times. I also took observation notes to compare data to transcriptions. Participants had the opportunity to review their transcription and were invited to make any changes. Three participants made changes to their transcriptions to ensure anonymity.

\section{Theoretical Framework}

The theoretical framework draws from the concepts of decolonial feminism (Manning, 2018) and intersectionality (Nefdt, 2019) to understand the phenomenon of leadership, and to explore the hidden forces of the colonial matrix of power, its origin, and its transformation (Holvino, 2008). This study is guided by the literature on women in leadership to answer the phenomenological research question: What are the leadership experiences of Latin American women in the GTA?

A decolonial feminism approach allows exploration of the ways Latin American women overcome coloniality in leadership. Decolonial theory critiques Eurocentric hegemonic patterns of knowledge and claims of the universality of Western ontology (Manning, 2018). The decolonial feminist approach considers the transformation of colonial relations of power and colonial ways of relating to women that continue to persist in our society, a concern that "resonates with and builds on the work of many postcolonial thinkers, as well as transnational and women-of-colour feminists" (Mendez, 2019, p. 9).

A decolonial feminism approach enables us to identify positionality and representation of the key barriers to engaging in research with marginalized "Others" (Manning, 2018). Decolonial feminism allows the possibility of overcoming the coloniality and acknowledges power across scales (Lugones, 2010; Maese-Cohen, 2010). Lugones (2010) and MaeseCohen (2010) would agree that minority women have been dehumanized through the perception of being weak and unable to perform difficult tasks as we continue centering our analysis on the patriarchy.

The application of intersectionality is also necessary. Intersectionality takes a variety of operational variables such as gender, race, ethnicity, culture, and class, as constituting a single diverse subject matter, as opposed to viewing all of these aspects individually (Crenshaw, 2017; MaeseCohen, 2010). Intersectionality allows researchers to examine the intersections or relationships and attempts to theorize the overlapping forms of oppression (Nefdt, 2019). An "intersectional approach does not treat race, class, gender, ability, and sexuality as autonomous categories but seeks to examine their interaction in understanding leadership identity, behavior, and effectiveness" (Sanchez-Hucles and Davis, 2010, p. 176). Also, 
intersectionality focuses on the experiences of a group with a disadvantaged status (Cole, 2009) and these observations reveal how intersectionality shapes the experiences of minority women (Crenshaw, 2017). Hence, my approach to intersectionality focuses on specific intersections/interactions, and dominant frames of oppression that generate anxieties in minority women's careers goals and actions. Latinas live within intersectionality, where the mechanism of oppression has historically marginalized minority groups, reinforcing a form of identity or inequality (Dhamoon, 2015; Sloan, Joyner, Stakeman, \& Schmitz, 2018). Sloan et al. (2018) argue that society intentionally or not tends to provide opportunities, first, for those with privilege and to limit those without. Sloan et al. (2018) present a story of a Latin women, named Teresa, who immigrated from Venezuela to the United Kingdom with a student visa, and how she was marginalized. Teresa recounts, Latina women are often asked to explain themselves, whether they are from the United Kingdom or not. They assume we are all from the same country - Brazil, even though they speak Portuguese and not Spanish - and ask if we know how to salsa - which is from Cuba - and if we've been to Carnival in Rio de Janeiro. If we speak with an accent different from their own, we are often as if spoken to children, followed by 'Do you understand?' (pp. 100).

\section{Ethical Considerations}

Ethical approval was obtained from Ryerson University's research ethics board. Participants' consent was obtained before interviews. They were reassured about confidentiality in the reporting of the study findings and were given the option to withdraw from the study at any time.

\section{Data Analysis}

A phenomenological analysis of the interview transcripts was conducted to develop a textual description of the participants' experiences and structural descriptions to convey an overall essence of the experience (Creswell, 2007). As the first step, I bracketed where no position is taken either for or against (Groenewald, 2004). That is, I set aside my own experiences, bias while analyzing the data, and preconceived notions. Second, I read the transcriptions to grasp a general sense of the phenomena (Giorgi, 2012). Third, while simultaneously manually coding, I read the transcriptions several times to delineate units of meaning, considering the significance of times a meaning was mentioned (Groenewald, 2004). Fourth, I clustered themes or grouped units of meaning to capture the essence and to form themes (Groenewald, 2004; Giorgi, 2012; Padilla-Díaz, 2015). Fifth, I summarized 
each interview, validating it by returning to the informant to determine if the essence of the interview had been correctly captured. Sixth, the descriptive and reflective notes (field notes) were compared. And, seventh, I extracted statements and unique themes and made a composite summary (Groenewald, 2004), using an Excel spreadsheet.

\section{Validity}

This phenomenological research study contributed to an understanding of the truth. For a Latin American woman residing in Canada, the study benefited from my background as a minority woman, as I experienced similar barriers; However, I bracketed myself consciously to understand the participants' perspective. Participants each received a copy of their transcript and were asked to review it. Some participants were asked follow-up questions or clarifications. The validity of the results and the interpretations are based on direct quotes from the data (Stiles, 1993). These approaches served as a tool for increasing the trustworthiness and reliability of the data.

\section{Participants}

The primary data collection comes in the form of in-depth, semistructured individual interviews. I interviewed 10 participants comprising

\section{Table 1:}

Study Population Profile.

\begin{tabular}{|c|c|c|c|c|c|}
\hline & $\begin{array}{l}\text { Industry } \\
\text { Sector }\end{array}$ & Job Title (Latest) & Country & $\begin{array}{l}\text { Arrived } \\
\text { in } \\
\text { Canada }\end{array}$ & Pseudonym \\
\hline 1 & Social work & Executive Director & Mexico & 2001 & Luciana \\
\hline 2 & $\begin{array}{l}\text { Financial } \\
\text { Industry }\end{array}$ & $\begin{array}{l}\text { Associate Vice- } \\
\text { President }\end{array}$ & Venezuela & 2000 & Natalia \\
\hline 3 & $\begin{array}{l}\text { Radio \& } \\
\text { Television }\end{array}$ & CEO \& Host & Argentina & 1970 & Olivia \\
\hline 4 & $\begin{array}{l}\text { Non-profit } \\
\text { organizations }\end{array}$ & Founder/President & Ecuador & 1966 & Valentina \\
\hline 5 & Social Work & Manager & Chile & 1974 & Clara \\
\hline 6 & $\begin{array}{l}\text { Non-profit } \\
\text { organizations }\end{array}$ & President & Colombia & 2001 & Gloria \\
\hline 7 & $\begin{array}{l}\text { Beauty } \\
\text { Industry }\end{array}$ & CEO \& Founder & Colombia & 2001 & Elena \\
\hline 8 & Law & Lawyer & El Salvador & 1990 & Ana \\
\hline 9 & Technology & $\begin{array}{l}\text { Senior Account } \\
\text { Manager }\end{array}$ & Peru & 2010 & Manuela \\
\hline 10 & Social Work & Social Worker & Colombia & 1980 & Jimena \\
\hline
\end{tabular}


Latin American women (from Argentina, Colombia, Chile, Ecuador, El Salvador, Mexico, Peru, and Venezuela) in leadership positions in the Greater Toronto Area (GTA). They were women immigrants to Canada who were born in the respective Latin American countries and spoke Spanish. An early decision was taken to limit the number of participants based on location and ethnic background to undertake a more in-depth study. Through snowballing, a total of 36 people was approached for inclusion in the study. Among those approached, 10 accepted the invitation to participate and have been given pseudonyms aiming to humanize them and voice their concerns louder. Table 1 lists the women who participated in this study. They have been in Canada for an average of 30 years, which allowed them to narrate a rich lived experience in their career paths and in leadership positions.

\section{RESULTS}

\section{Understanding Latin American Women in Leadership. What is Leadership for these Latin American Women Leaders?}

Leadership is a highly multi-faceted subject, and it is a mixture of many factors that help determine why some people become great leaders. Leadership has been described in relation to traits, competencies, character, personality, emotional intelligence, and situational context (Eagly \& Carli, 2012). In addition, it has been examined in terms of the ability in decision making (D'Andrea, 2017, 2018). Definitions in leadership have in common a focus on the interpersonal influence that uses power and authority to encourage others to act toward the achievement of goals (Sanchez-Hucles and Davis, 2010; Yukl, 2009). Leaders are enablers and influencers. Leaders "wield considerable power and often are attributed with transforming our lives through social or organizational change .... be it for good or evil. Leadership can dramatically impact our lives" (Rast III, Hogg \& Randsley de Moura, 2018, p. 9). Leadership involves more than being put into a leadership role, developing or acquiring new skills, and adapting to the position; it consists of an identity shift (Ibarra, Ely \& Kolb, 2013).

Leadership is a process in which an individual influences a group of individuals to achieve mutual purposes (Trinidad \& Normore, 2005; Rosari, 2019). However, a precise definition of leadership would consider numerous factors, including leadership style, and a perfect or ideal definition or leadership style would be unhelpful because various factors shape leadership (Trinidad \& Normore, 2005), including daily, lived experiences. In simple terms, leadership is socially constructed (Brown, 2012; Endres \& Weibler, 2017; Trinidad \& Normore, 2005). As a result, participants defined leadership 
in different terms based on their lived experiences. The most common words used to define leadership are depicted in Figure 1- Leadership Definition.

Being an immigrant is filled with doubts and insecurity; perhaps that is why immigrants need to believe in order to achieve their career goals; (2) hard-work as the means of achieving goals; (3) role-model to encourage others to follow your principles and leading by example; (4) motivate others by injecting enthusiasm and perhaps a little humor; keep asking questions; (5) vision by having a sense of direction and a long-term plan; (6) comfortable within one's shoes and by making an impact and impression on others; and (7) inspiring your team to be the best and helping them grow. Hence, the definition of leadership depends on the social space and individual lived experiences. Minority leaders construct their own aspirational definition of leadership; these "words" or "definitions" as shown in Figure 1 intertwine and construct the meaning of leadership. The leader will assess which variables need action to provide proper guidance to achieve common goals.

\section{Figure 1:}

Leadership Definition

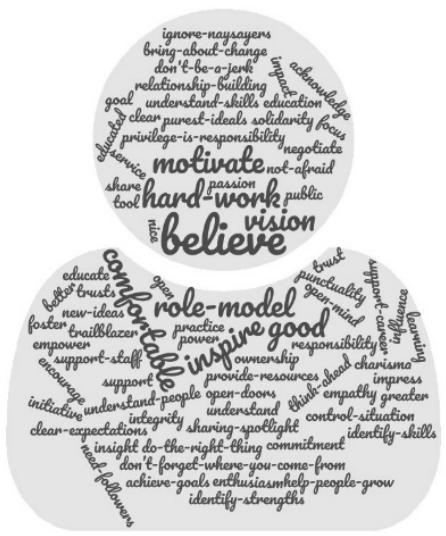

Source: D'Andrea (2020), https://www.wordclouds.com/

\section{Key Barriers to Leadership for Minoritie}

Minority women are faced with barriers that may prevent them from been considered for leadership positions (Hoyt \& Murphy, 2016; Rosette, Koval, Ma, \& Livingston, 2016; Trinidad \& Normore, 2005). If they do achieve a leadership position, they continuously need to assert themselves and work harder than their white female counterparts (Luciana). In a study with Latin American graduates of Canadian MBA programs, Hakak, Holzinger and Zikic (2010) found that the most commonly emphasized challenges or 
barriers were "English as a second language, cultural differences — or 'feeling foreign' - and subtle discrimination" (p. 6). In this study, several factors affected or restricted their career accomplishments, such as gender relations, discrimination, negative stereotypes, language barriers and accent, scarcity of networks and mentors, and the struggle to work-life (family) balance.

\section{Gender Relations (women vs men and women vs women)}

The process of decolonization stems from gender relations, and the colonial constructs of the role of women and men in society (Schiwy, 2007). For instance, women are viewed as homemakers. One participant says, "Men are not demanded the same things in society" (Luciana). Natalia asks "why women have to be the ones who always have to think about home and work?" She adds that women are often "assigned by gender rather than by skills." The literature on gender differences is extensive, and, for example, has catalogued men as having more self-confidence and taking more risks in leadership positions (See Alan, Ertac, Kubilay, \& Loranth, 2020). Women were reported as having a lower power motivation than men (Schuh, Bark, Van Quaquebeke, Hossiep, Frieg, Van Dick, 2014).

The debate about gender differences continues to this day (See also Ardila, Rosselli, Matute, \& Inozemtseva, 2011; Croson, \& Gneezy, 2009; Hyde, 2014). However, it is clear that the barriers are not solely between women and men, but also between women and other women. The literature (Mann, 1995) and interviews reveal that women who have achieved positions of power and authority often hesitate to help younger women to advance in their careers for several reasons. Mann (1995) offered one potential explanation for this and argued that the reason for this unwillingness to help younger women is because very often women have risen well in the ranks by

[E]xemplifying male attitudes, language and behaviour. They then do not want to be identified with other women. In other cases, women who have reached the top echelons after many years of hard work and patience may resent younger women who want quick advancement up to the executive ladder without working as hard as they had to. Another reason may be that, in many cases, women in top positions have to fight for their own survival and do not have the strength to undertake an additional struggle to circumvent the obstacles that prevent other women's advancement. (pp.14)

Participants shared with me how others, including women, tried to sabotage their careers by undermining their positions and capabilities. Luciana says, "No matter how bad someone was trying to undermine me, my 
hard work, being prepared, being on time, knowing my work, makes it possible to supersede those challenges." Gloria exclaims, "I don't know why she didn't like me, and I don't know because I never did anything to her." Clara adds "With the new senior administration in place, she started going after me and accusing me of stealing." Ana says that she had issues with other women as well. Anna asserts, "I feel they are in competition with me, instead of working together." This unwillingness to work collegially and judging other races' intersectionality on the impact of how race and social class are played out in the daily lives, in this case, at the workplace, which is more accentuated with minority groups.

\section{Racial and Gender Discrimination}

The Canadian Human Rights Commission defined Discrimination as "an action or a decision that treats a person or a group badly for reasons such as their race, age or disability. These reasons, also called grounds, are protected under the Canadian Human Rights Act" (Canadian Human Rights, n.d.). The grounds are listed as race, national or ethnic origin, colour, religion, age, sex, sexual orientation, gender identity or expression, marital status, family status, disability, genetic characteristics, and a conviction for which a pardon has been granted or a record suspended (Canadian Human Rights, n.d.).

There is an underrepresentation of minorities being promoted to leadership positions due to discrimination and bias in Western nations (Cohen \& Huffman, 2007; Cook \& Glass, 2013). Valentina explains that when she came to Canada, "It was very difficult. It was particularly so as you were a 'newcomer' or a 'visible minority.' You couldn't rise up to certain levels, but as I experienced it, there was a lot of racism and discrimination."

Clara states that she "suffered a lot of racism" during her life in Canada. For instance, while in a leadership position and as the only minority woman, the new administration of a health institution blamed her for stealing money. Clara says that the new administration thought of her "as inefficient, lazy and not honest" and she felt she always needed to prove her worth. Kay and Gorman (2012) argue that racial minorities are repeatedly asked to prove their competence before being trusted with tasks.

Unfortunately, minority leaders are often put on the alert and questioned, and their leadership practices are contested in one form or another. Empirical evidence suggests that minority employees are held to stricter standards for demonstrating ability (Foschi 2009), which is often extreme. Clara explains that she was a bit naïve earlier in her career and instead of challenging the discriminatory/racists practices, she quit the job, 
which she now regrets. That was a lesson for Clara to stand up for any subsequent discriminatory act.

All participants experienced discrimination. Elena said that when she was a newcomer to Canada, immigrating from the U.S., she was told by her neighbours and new friends, "You just arrived. Oh, you can clean my house." On the other hand, Gloria perceives discrimination in the entire Latin community, as she argues, "The discrimination is not just about the women; discrimination is also present within the community. On the other hand, Jimena shares her experiences at work,

I notice a little bit; they treat me a little different. Now, looking back, I have many experiences in my life, many experiences working as a social worker, and I could say that at that time, and that still right

now, I would say that discrimination exists a little bit, and so I went home, feeling a little bit, I would say, you know, questioning myself. Racial and gender discrimination exist and are a global concern for a number of reasons, including economic ones. Gender discrimination can lead to both financial losses and decreased innovation (Triana, Jayasinghe, Pieper, Delgado, \& Li, 2019). In 2016, U.S.A. employers spent more than \$2 billion in financial awards in legal cases of gender discrimination (Triana et al., 2019). In Canada, similar cases have been reported (Beaton, Tougas, Rinfret, \& Monger, 2014).

\section{Negative Stereotypes}

When someone speaks a different language than our own, there are still built-in stereotypes. Fiske (2016) defines stereotype as a cognitive bias, "a belief that characterizes people based merely on their group membership" (p. 13). There is no doubt minority women can bring unique and essential perspectives that serve to promote positive social outcomes to organizations and the community. However, the realization of these potential outcomes "can be hampered by the disadvantage female leaders experience as the target of negative stereotype-based expectations" (Hoyt \& Murphy, 2016, p. 387). These stereotypical notions include the preconceived notions of social identity, undermining achievement; for instance, maintaining the gender construct that "women are caregivers" and "men are in charge" (Hoyt \& Murphy, 2016).

Stereotyping comes from everywhere, but it tends to affect a community when it comes from the top government officials. Olivia says that while at a Latin American festival in the city, a government official opened the event and said, "It is a privilege for me to be here tonight; I've been in a lot of festivals. The Indian community is very good because they're working 
together, the Chinese community is very good because the family are always together and study; I am happy to be in the Spanish community because all the time is Fiesta!"

Olivia states, "Everybody is laughing and clapping, but I don't, because if you read between the lines of what is he saying, he's saying the Indian community are working together, the Chinese are all together, the Spanish are fiesta, fiesta. The government sees the Spanish community as just fiesta, fiestera." Clara, with more than four decades of work experience in Canada, states,

We are viewed as tropical birds who are very passionate, very colourful, very bright and nice to have around. Most people like having me around because of who I am. Still, I hate it because, at the same time, they don't see me as the true person that I am: that is, not just this colorful bird, but actually a woman who has a purpose, who is smart and has a lot of good ideas and who is not passionate when it comes to my thinking academically or administratively. People keep me because I'm very smart, I'm a very hard worker, and I'm focused.

In addition, a work colleague asked Luciana, "How come don't know about the drug lord if you are Mexican?" And, as Gloria was looking to change careers from the service industry, the manager told her, "You're an immigrant; you need this job." These stereotype-based expectations threaten women's confidence and can contribute to feelings of inferiority (See Quijano, 2000), and a lack of belonging and performance impairment (Hoyt \& Murphy, 2016), resulting in underperformance or withdrawal from the workplace. All participants in this study at one point of their careers experienced it and removed themselves from situations where negative stereotypes were orbiting. Hoyt \& Murphy (2016) argue that stereotyping affects academic performance in Latino/as, in particular in those populations that are vulnerable. These disadvantages contribute to intersectional invisibility, creating a social system of oppression and forms of social inequity (Rosette, Koval, Ma, \& Livingston, 2016).

\section{Language Barriers \& Accent}

From stereotypes to language barriers, including accents: they also impact the perception of a minority's abilities in the workplace and question leadership potential. Clara explains that the lack of fluency in the English language was a significant concern early in her career, so much so that during a work presentation, she cried because she was not sure that the audience understood her because of her accent. Although she has become proficient in 
her English language skills and has become a talented speaker over the years, her accent is still questioned.

In the workplace, accent has been perceived as negative and unfavourable. Munro (2003) asserts that "accent is just one of a number of characteristics, along with skin color, dress, or mannerisms, that may be used to identify someone as 'foreign' or 'different' and that can serve as an excuse for discriminatory treatment" (p. 39). Some people regard an accent itself as an undesirable characteristic and have negative attitudes about the speaker, which unintentionally may limit promotions (Munro, 2003). In the last four decades, evidence of discriminatory attitudes toward accented speakers has been reported in a wide range of literature (Freynet \& Clément, 2019; LippiGreen, 2012; Munro, 2003, 2008; Raisler, 1976).

Participants understood their limitations with the English language concerning the advancement of their careers, and some of these women have learned to accept it. As Natalia states, "I have learned to accept my accent, I am rather more concerned about conveying a clear message." Olivia says, "People do laugh about accents, including our own Latin American community."

On the other hand, others feel apologetic. Valentina often apologizes for her accent: "Sorry, my English is not very good." It's important to note that Valentina was invited to audition for a well-known television network in Canada as an anchor. She was declined the job because of her accent and not being perceived as "minority enough." Jimena adds that accent discrimination is prominent in the way newcomers behave. During her workshops, she has experienced it, noticing that newcomers of all ages are always reluctant to raise their hands to ask questions because of a language barrier or an accent.

Although participants in the study know their language limitations, they all have a high level of self-confidence. It is relevant to note that most of them have been able to climb up the ladder because, often, their positions require them to speak their mother tongue. Also, several of the participants remain in the community where they have grown professionally and have been able to make a positive impact - noting that accent is not mistrusted in careers where the mother tongue language is required, nor is it a hindrance in the technology field.

\section{Scarce Networks \& Lack of Mentors}

Another barrier to the Latin American community is the lack of a network and mentors. It is understood that mentors can make a difference in getting on the inside track and in career growth. Mentoring and role models play a crucial role in women's career path advancement (Brown, 2005; 
Dunbar \& Kinnersley, 2011; Ely, Ibarra, \& Kolb, 2011; Hill \& Wheat, 2017). Latin American MBAs in Canada see networks as potential enablers of career success (Hakak, Holzinger and Zikic, 2010). Studies suggest that women need mentors to serve as role models, people who can show them how to advance despite existing barriers (Kurtz-Costes, Helmke, \& Ulku-Steiner, 2006). The shortage of minority women, in particular Latin American women, at upper levels of organizations, creates a dearth of potential female mentors/role models within the community. Hoyt \& Murphy (2016) state that role models could help buffer stereotype reactions.

Although there may be no deliberate intention to exclude minorities, "whites are likely to receive more on-the-job training, more mentoring, and more opportunities to perform challenging tasks that build skills" (Kay \& Gorman, 2012, p. 3). This results in the underrepresentation of minority leaders, and hence, a lack of networks and, by extension, mentors. Clara shares her sentiment that the Latin American community in Canada lacks networks:

First of all, we don't have networks. You see it in the hospital. When I worked at the hospital, most of the women there knew each other from youth because they went to the same school, so, they know each other, they lived in similar neighborhoods ... They liked me because we are progressive; that we are feminist women and they like having that connection with a Latin American was kind of nice. Still, I wasn't part of the group, so, if anything happened in my position, I would be the first person to go, because, I didn't have the network to protect me.

McGuire (2000), states that minorities have fewer effective social networks. Manuela states, "Networking is such an important skill, but a lot of people came to me, and that tells me 'I don't know how to do the networking thing. I see you talking A, B, C, D but I don't know how to do it, can you give help?"'

On the other hand, networking is gendered as it helps men (particularly in mid-late career) advance in management more than women (Tharenou, 2005) because men tend to allocate more time for networking, whereas women (in particular married ones) are trying to balance home and work. Networking is also time-consuming (Cross, 2010) and conflicting, as women try to achieve a work-life balance. Luciana states, "Yes, I network, but I try to keep a balance because if I work until 10 p.m., I'm still expected to be in the office by 9 a.m. next day; And there are things I need to get done at work before 9 a.m. and at home." Then, there is a tension between work and one's outside life that might impede effective networking. 


\section{Struggle to Achieve Work-life Balance}

Work-life balance is a shared concern among women, and in particular, for minority women in Western societies (Ko, Kachchaf, Ong, \& Hodari, 2013). In this study, work-life balance is described as "an individual's ability to meet their work and family commitments, as well as other non-work responsibilities and activities" (Delecta, 2011, p. 186). Work-life balance involves fulfilling the demands satisfactorily in the three basic areas of life; work, family, and private (Delecta, 2011).

In the quest for work-life balance, employers often believe that women are less committed to work and, hence, men are perceived as more able (Cross, 2010). Women are still viewed as the primary caregivers in a relationship and thus, are burdened with domestic responsibilities (Cross, 2010). Although men have been able to carry some of the household responsibilities over the last decade, women still shoulder the largest burden (Cross, 2010). Participants reported concern over being able to have both a family and a successful career. They often chose family over their careers, which limited their career prospects. In fact, nine out of ten participants in this study have children. The literature asserts that having children remains a significant barrier for women's career progression (Cross, 2010), in particular when women often have the feeling of wanting to do it all (Campbell, 2009).

Luciana plans for early retirement to spend more time with her family. For years, she explains, she has been struggling to find a work-life balance. As a part of discriminatory practices during her career, Valentina explains that she postponed her career twice due to her pregnancies, as she says, "I got pregnant and couldn't continue neither TV nor my real estate work." Gloria, as well, lost two jobs due to pregnancy and caring for her aging mother. As a business entrepreneur and single mother, Elena also finds a lot of challenges in maintaining a work-life balance, running her business and family; at times, her finances pay the price.

Family-work and cultural factors will always conflict with paid work, and the onus generally rests with the women. In a study on working women and homemakers in Europe, scholars found that working women can face tensions, as in a context of an inegalitarian distribution of domestic tasks, because as they have to carry out two roles at the same time: doing their jobs and taking care of the home, where they received little recognition and no compensation, resulting in lower socio-emotional well-being (Connerley, \& $\mathrm{Wu}, 2016)$.

Manuela reiterates that "wives enable husbands, and women end up taking more household responsibilities," which affect women's careers. The 
well-being and emotional state of women are at stake. The ability of minority women to manage their work-life balance is shaped by the intersectionality of gender and societal expectations and the dominant patriarchal society, where the unequal distribution of tasks is assumed. High social status may alleviate some of the domestic burdens; however, still, women manage the household. When asked in an interview "Do you actually change diapers?" Donald Trump responded, "No, I don't do that." Trump added, "There's a lot of women out there that demand that the husband acts like the wife, and you know, there's a lot of husbands that listen to that." (Kaczynski \& Apper, 2016, paras. 2-3).

In our daily lives, minority women keep getting stereotyped and are put on the margins. It also happened to me, as a Latin American woman living in Canada for about 30 years. I have experienced all those barriers, I have experienced discrimination and stereotyping at work, the limitation of climbing the ladder because of my accent or lack of social class. I was told once at work that "I was nothing," and was yelled at for not taking the blame. Often, we have to work harder because we need to constantly prove to others that we are capable and that we matter, and hence, there is a constant struggle, I find, with work dynamics. As well, the struggle continues at home, where the cultural divide continues, as minority women with children try to manage a life balance.

\section{Study Limitations}

This qualitative research facilitates an understanding of the significant barriers that affect Latin American women within the Canadian context. The limited number of informants who contributed to the study allows for a longer follow-up relative to other research in this area. At times participant's language barriers limited data gathering, as it was conducted in English. Most of the participants in this study held a position where their first native language (Spanish) was required, which allowed them to progress in their careers with some ease. I would have liked to have spoken with more Latin American women in leadership positions who self-isolate from their community and fully immerse themselves into the Western culture.

\section{DISCUSSION AND CONCLUSIONS}

The Latin American women in this study have been able to work within the power structure to acquire leadership over time. Barriers are still present and impact their career progression, causing them to re-evaluate their career aspirations. Ethnic stereotypes, sometimes of a subtle nature, are prejudicial to Latin women immigrant workers. For instance, Manuela feels responsible for her career not just as an individual, but for the entire continent. 
Manuela stated that she thinks that there are "a thousand people waving at her shoulders" because she fears that if she fails, she will be judged, not as an individual, but as a representative of the entire continent, and her failure will reinforce stereotypes. In the face of stereotypes, discrimination, family and other socio-cultural pressures for Latin American women, there is an additional great sense of responsibility and burden. As Manuela says: "I'm not representing one country, I'm representing a whole continent." Indeed, minority groups have "a chip on their shoulder" (Sensoy \& DiAngelo 2017, p. 70).

The absence of minority women in leadership positions affects the younger generation. The lack of Latin American women in the ranks of senior management is still a telling sign that the whole process of selection, recruitment and promotion in organizations is in need of an overhaul. How can they overcome colonial situations? This study illuminates the conditions under which these barriers might be overcome as a part of the decoloniality. Creating a culture where role models are available is essential, and in general, organizations need to strengthen policies promoting work-life balance. Again, the responsibility should not fall solely on women, and men need to be educated and also increase participation in domestic household responsibilities.

Intersectionality matters. Race and gender bias, as well as language barriers, have been identified as impediments to minority women's access, retention, and progress in their careers. The experience of the stereotype threat processes in leadership contexts extends beyond women, minority women. There is a need to place a greater emphasis on understanding the role of race, ethnicity, sexual orientation, age, and other types of diversity within the minority community.

This paper seeks to recognize minority women's invisibility in leadership in the mainstream by not ignoring their differences in terms of race or class, but by acknowledging these differences, helping to reframe the conversation and undertaking corresponding research so that leadership becomes more inclusive. We must change the construct of minority women from decolonial and marginalized to a louder and visible voice.

\section{IMPLICATIONS}

My findings inform an analysis of how the intersection of race and gender shapes the leadership experiences of minority women in a dominant patriarchal society. This research calls on organizations to address stereotypes and discrimination and improve collaborations and opportunities for minority women. There is a need to create and encourage a mentorship program that 
supports Latin American women. Human resources professionals can foster this practice by helping women gain experience in, for example, mentorship relationships. I am hoping this research can serve as a model for a larger-scale study on each topic in the future.

\section{REFERENCES}

Alan, S., Ertac, S., Kubilay, E., \& Loranth, G. (2020). Understanding gender differences in leadership. The Economic Journal, 130(626), 263-289. https://doi.org/10.1093/ej/uez050

Ardila, A., Rosselli, M., Matute, E., \& Inozemtseva, O. (2011). Gender differences in cognitive development. Developmental psychology, 47(4), 984. https://doi.org/10.1037/a0023819

Brown, S. A. (2012). Exploring transformative organizational change through the social constructs of leadership, culture, and learning (Order No. 3524080). Available from Business Premium Collection; ProQuest Dissertations \& Theses A\&I; ProQuest Dissertations \& Theses Global. (1038972436). Retrieved from http://ezproxy.lib.ryerson.ca/login?url=https://searchproquestcom.ezproxy.lib.ryerson.ca/docview/1038972436?accountid=13631

Campbell, V. (2009). Advice from the top: What minority women say about their career success. Praeger ABC-CLIO.

Canadian Human Rights Commission. (n.d.). What is discrimination? Retrieved from https://www.chrc-ccdp.gc.ca/eng/content/what-discrimination

Carli, L. L., \& Eagly, A. H. (2001). Gender, hierarchy, and leadership: An introduction. Journal of Social Issues, 57(4), 629-636. https://doi.org/10.1111/0022-4537.00232

Collins, P.H. (2015). 'Intersectionality's definitional dilemmas', Annual Review of Sociology, 4l(1), 3-20. https://doi.org/10.1146/annurev-soc-073014112142

Chin, J. L. (2010). Introduction to the special issue on diversity and leadership. American Psychologist, 65(3), 150. https://doi.org/10.1037/a0018716

Cole, E. R. (2009). Intersectionality and research in psychology. American psychologist, 64(3), 170. https://doi.org/10.1037/a0014564

Connerley, M. L., \& Wu, J. (Eds.). (2016). Handbook on well-being of working women. London: Springer.

Cook, A., \& Glass, C. (2013). Glass cliffs and organizational saviors: Barriers to minority leadership in work organizations? Social Problems, 60(2), 168187. https://doi.org/10.1525/sp.2013.60.2.168

Corbeil, J. (2019, November). Insight on the Hispanic/Spanish speaking or descent population in Canada - based on 2016 census. Poster presented for the Canadian Hispanic Congress, Toronto, ON.

Creswell, J. W., \& Poth, C. N. (2007). Qualitative inquiry and research design: Choosing among five approaches. Sage publications. 
Croson, R., \& Gneezy, U. (2009). Gender differences in preferences. Journal of Economic Literature, 47(2), 448-74. https://doi.org/10.1257/jel.47.2.448

Cohen, Philip N., and Matt L. Huffman. 2007. Black under-representation in management across U.S. labor markets. Annals of the American Academy of Political and Social Science 609, 181-99. https://doi.org/10.1177/0002716206296734

Cross, C. (2010). Barriers to the executive suite: evidence from Ireland. Leadership \& Organization Development Journal, 31(2), 104-119. https://doi.org/10.1108/01437731011024376

Crenshaw, K. W. (2017). On intersectionality: Essential writings. The New Press. D'Andrea, M. (2017). Inside the World of Arts Councils: Artistic Excellence in the Peer Review Process for Arts Funding. The International Journal of Social, Political and Community Agendas in the Arts, 12(4), 25-44. https://doi.org/10.18848/2326-9960/cgp/v12i04/25-44

D'Andrea, M. (2018). Groupthink tensions: Analysis of the peer-review process for arts funding. The American Journal of Arts Management, 6(1), 1-29.

Ely, R. J., Ibarra, H., \& Kolb, D. M. (2011). Taking gender into account: Theory and design

for women's leadership development programs. Academy of Management Training and

Education, 10(3), 474-493. https://doi.org/10.5465/amle.2010.0046

Delecta, P. (2011). Work-life balance. International Journal of Current Research, $3(4), 186-189$.

Dhamoon, R. (2015). A feminist approach to decolonizing anti-racism: Rethinking transnationalism, intersectionality, and settler colonialism. Feral Feminisms, 4, 20-37.

Dunbar, D. P., \& Kinnersley, R. T. (2011). Mentoring female administrators toward leadership success. Delta Kappa Bulletin, 77(3), 17-24.

Eagly, A. H., \& Carli, L. L. (2012). Women and the labyrinth of leadership. Contemporary issues in leadership, 147-162. https://doi.org/10.4324/9780429494000-17

Eagly, A. H., \& Chin, J. L. (2010). Diversity and leadership in a changing world. American psychologist, 65(3), 216. https://doi.org/10.1037/a0018957

Eagly, A. H., \& Johannesen-Schmidt, M. C. (2001). The leadership styles of women and men. Journal of Social Issues, 57(4), 781-797. https://doi.org/10.1111/0022-4537.00241

Endres, S., \& Weibler, J. (2017). Towards a three-component model of relational social constructionist leadership: A systematic review and critical interpretive synthesis. International Journal of Management Reviews, 19(2), 214-236. https://doi.org/10.1111/ijmr.12095

Fiske, S. T. (2016). Prejudice, discrimination, and stereotyping. In R. Biswas-Diener \& E. Diener (Eds), Noba textbook series: Psychology. Champaign, IL: DEF publishers. https://doi.org/nobaproject.com. 
Foschi, Martha. 2009. Gender, performance level, and competence standards in task groups.

Social Science $\quad$ Research 33, 447-57. https://doi.org/10.1016/j.ssresearch.2008.10.004

Freynet, N., \& Clément, R. (2019). Perceived accent discrimination: Psychosocial consequences and perceived legitimacy. Journal of Language and Social Psychology, 38(4), 496-513. https://doi.org/10.1177/0261927x19865775

Giorgi, A. (2012). The descriptive phenomenological psychological method. Journal of Phenomenological Psychology, 43(1), 3-12. https://doi.org/10.1163/156916212X632934

Gotsis, G., \& Grimani, K. (2016). Diversity as an aspect of effective leadership: Integrating and moving forward. Leadership \& Organization Development Journal, 37(2), 241-264. https://doi.org/10.1108/lodj-06-2014-0107

Groenewald, T. (2004). A phenomenological research design illustrated. International Journal of Qualitative Methods, 3(1), 42-55. https://doi.org/10.1177/160940690400300104

Hakak, L. T., Holzinger, I., \& Zikic, J. (2010). Barriers and paths to success: Latin American MBAs' views of employment in Canada. Journal of Managerial Psychology, 25(2), 159-176.

Hiebert, D. (2015). Ethnocultural minority enclaves in Montreal, Toronto and Vancouver. Institute for Research on Public Policy. Retrieved from https://irpp.org/research-studies/ethnocultural-minority-enclaves-inmontreal-toronto-and-vancouver/

Hill, L. H., \& Wheat, C. A. (2017). The influence of mentorship and role models on university women leaders' career paths to university presidency. The Qualitative Report, 2090-2111. https://nsuworks.nova.edu/tqr/vol22/iss $8 / 2$

Hoyt, C. L., \& Murphy, S. E. (2016). Managing to clear the air: Stereotype threat, women, and leadership. The Leadership Quarterly, 27(3), 387-399. https://doi.org/10.1016/j.leaqua. 2015.11.002

Hyde, J. S. (2014). Gender similarities and differences. Annual review of psychology, 65, 373-398. https://doi.org/10.1146/annurev-psych-010213-115057.

Ibarra, H., Ely, R., \& Kolb, D. (2013). Women rising: The unseen barriers. Harvard Business Review, 91(9), 60-66.

Kaczynski, A., \& Apper, M. (2016, April 24). Donald Trump thinks men who change diapers are acting "like the wife". BuzzFeed News. Retrieved from https://www.buzzfeednews.com/article/andrewkaczynski/donald-trumpthinks-men-who-change-diapers-are-acting-like-t

Kay, F. M., \& Gorman, E. H. (2012). Developmental practices, organizational culture, and minority representation in organizational leadership: The case of partners in large US law firms. The Annals of the American Academy of Political and Social Science, 639(1), 91-113. https://doi.org/10.1177/0002716211420232 
Ko, L. T., Kachchaf, R. R., Ong, M., \& Hodari, A. K. (2013, January). Narratives of the double bind: Intersectionality in life stories of women of color in physics, astrophysics and astronomy. In AIP Conference Proceedings (Vol. 1513, No. 1, pp. 222-225). American Institute of Physics. https://doi.org/10.1063/1.4789692

Kurtz-Costes, B., Helmke, L. A., \& Ulku-Steiner, B. (2006). Gender and doctoral studies: Perceptions of Ph.D. students in an American university. Gender and Education, 18(2), 137-155. https://doi.org/10.1080/09540250500380513

Laverty, S. M. (2003). Hermeneutic phenomenology and phenomenology: A comparison of historical and methodological considerations. International Journal of Qualitative Methods, 2(3), 21-35. https://doi.org/10.1177/160940690300200303

Lippi-Green, R. (2012). English with an accent: Language, ideology and discrimination in the United States. Routledge. https://doi.org/10.4324/9780203348802

Lugones, M. (2010). Toward a decolonial feminism. Hypatia, 25(4), 742-759. https://doi.org/10.1111/j.1527-2001.2010.01137.x

McGuire, Gail M. (2000). Gender, race, ethnicity, and networks: The factors affecting the status of employees' network members. Work and Occupations 27, 50123. https://doi.org/10.1177/0730888400027004004

Maese-Cohen, M. (2010). Introduction: Toward planetary decolonial feminisms. Qui Parle: Critical Humanities and Social Sciences, 18(2), 3-27. https://doi.org/10.1353/qui.0.0015

Mann, S. (1995). Politics and power in organizations: why women lose out. Leadership \& Organizational Development Journal, 16(2), 9-15. https://doi.org/10.1108/01437739510082271

Manning, J. (2018). Becoming a decolonial feminist ethnographer: Addressing the complexities of positionality and representation. Management Learning, 49(3), 311-326. https://doi.org/10.1177/1350507617745275

Mendez, X. (2015). Notes toward a decolonial feminist methodology: Revisiting the race/gender matrix. Trans-scripts, 5, 41-56.

Munro, M. J. (2003). A primer on accent discrimination in the Canadian context. TESL Canada Journal, 38-51. https://doi.org/10.18806/tesl.v20i2.947

Munro, M. J. (2008). Foreign accent and speech intelligibility. Phonology and Second Language Acquisition, 193-218. https://doi.org/10.1075/sibil.36.10mun

Nefdt, A. (2019). A persisting minority - narratives of women in corporate leadership, Agenda, 33(1), 129-141. https://doi.org/10.1080/10130950.2019.1598774

Padilla-Díaz, M. (2015). Phenomenology in educational qualitative research: Philosophy as science or philosophical science. International Journal of Educational Excellence, $1(2)$, 101-110. https://doi.org/10.18562/ijee.2015.0009 
Pew Report Center. (2015). Women and leadership: public says women are equally qualified, but barriers persist. Washington, D.C.: Pew Research Center.

Quijano, A. (2000). Coloniality of power and Eurocentrism in Latin America. International Sociology, 15(2), 215-232. https://doi.org/10.1177/0268580900015002005

Raisler, I. (1976). Differential response to the same message delivered by native and foreign speakers. Foreign Language Annals, 9(3), 256-259. https://doi.org/10.1111/j.1944-9720.1976.tb03221.x

Rast III, D. E., Hogg, M. A., \& Randsley de Moura, G. (2018). Leadership and social transformation: The role of marginalized individuals and groups. Journal of Social Issues, 74(1), 8-19. https://doi.org/10.1111/josi.12253

Rosari, R. (2019). Leadership definitions applications for lecturers' leadership development. Journal of Leadership in Organizations, 1(1), 17-28. https://doi.org/10.22146/jlo.42965

Rosette, A. S., \& Livingston, R. W. (2012). Failure is not an option for Black women: Effects of organizational performance on leaders with single versus dualsubordinate identities. Journal of Experimental Social Psychology, 48(5), 1162-1167. https://doi.org/10.1016/j.jesp.2012.05.002

Rosette, A. S., Koval, C. Z., Ma, A., \& Livingston, R. (2016). Race matters for women leaders: Intersectional effects on agentic deficiencies and penalties. The Leadership Quarterly, 27(3), 429-445. https://doi.org/10.1016/j.leaqua.2016.01.008

Sanchez-Hucles, J. V., \& Davis, D. D. (2010). Women and women of color in leadership: Complexity, identity, and intersectionality. American Psychologist, 65(3), 171. https://doi.org/10.1037/a0017459

Schiwy, F. (2007). Decolonization and the question of subjectivity: Gender, race, and binary thinking. Cultural studies, 21(2-3), 271-294. https://doi.org/10.1080/09502380601162555

Schuh, S. C., Bark, A. S. H., Van Quaquebeke, N., Hossiep, R., Frieg, P., \& Van Dick, R. (2014). Gender differences in leadership role occupancy: The mediating role of power motivation. Journal of Business Ethics, 120(3), 363379. https://doi.org/10.1007/s10551-013-1663-9

Sensoy, O., \& DiAngelo, R. (2017). Is everyone really equal? An introduction to key concepts in social justice education. Teachers College Press.

Sloan, A., \& Bowe, B. (2014). Phenomenology and hermeneutic phenomenology: The philosophy, the methodologies, and using hermeneutic phenomenology to investigate lecturers' experiences of curriculum design. Quality \& Quantity, 48(3), 1291-1303. https://doi.org/10.1007/s11135-013-9835-3

Sloan, L., Joyner, M., Stakeman, C., \& Schmitz, C. (2018). Critical Multiculturalism and Intersectionality in a Complex World. NY, NY: Oxford University Press.

Stanford, J. H., Oates, B. R., \& Flores, D. (1995). Women' s leadership styles: a heuristic analysis. Women in Management Review, 10(2), 9-16. https://doi.org/10.1108/09649429510077421 
Statistics Canada (2016). Dictionary, Census of Population, 2016 Visible minority. Retrieved from https://www12.statcan.gc.ca/censusrecensement/2016/ref/dict/pop127-eng.cfm

Statistics Canada (n.d.). Visible minority of person. Retrieved from http://www23.statcan.gc.ca/imdb/p3Var.pl?Function=DEC\&Id=45152

Stryker, S. R. (2018). Language Barriers to Gender Equity in Senior Executive Leadership. Journal of Management Policy and Practice, 19(1), 111-120. https://doi.org/10.33423/jmpp.v19i1.1273

Telegram.com. (n.a.). Latinos in Canada. Retrieved from https://www.telegram.com/assets/microsites /hispanicheritage/article0007.html

Tharenou, P. (2005). "Women's advancement in management" in Burke, R.J. and Mattis, M.C. (Eds). Supporting Women's Career Advancement: Challenges and Opportunities, Edward Elgar Publishing, Northampton, MA. https://doi.org/10.1108/09649420610643439

Triana, M. D. C., Jayasinghe, M., Pieper, J. R., Delgado, D. M., \& Li, M. (2019). Perceived workplace gender discrimination and employee consequences: a meta-analysis and complementary studies considering country context. Journal of Management, 45(6), 2419-2447. https://doi.org/10.1177/0149206318776772

Trinidad, C., \& Normore, A. H. (2005). Leadership and gender: a dangerous liaison? Leadership \& Organization Development Journal, 26(7), 574-590. https://doi.org/10.1108/01437730510624601

Turchick-Hakak, L., Holzinger, I., \& Zikic, J. (2010). Barriers and paths to success: Latin American MBAs' views of employment in Canada. Journal of Managerial Psychology, 25(2), 159-176. https://doi.org/10.1108/02683941011019366

van Manen, M. (1997). Researching lived experience: Human science for an action sensitive pedagogy (2nd Ed.). London, Canada: The Althouse Press.

Yukl, G. (2009). Leadership in Organizations (6th ed.). Upper Saddle River, NJ: Prentice Hall.

MARISOL D'ANDREA, PhD, is a visual artist, illustrator, author, and multidisciplinary researcher. She is the author of "The Power of Artistic Thinking: Think Like an Artist and Innovate." She holds a doctoral degree in Leadership, Higher and Adult Education from the University of Toronto. This research study was initiated during her postdoctoral role at Ryerson University. Her major research interests lie in the area of leadership, arts, diversity, minority, and social justice. Email: marisol.dandrea@gmail.com

Manuscript submitted: October 22, 2020

Manuscript revised: January 2, 2021

Accepted for publication: March 5, 2021 